\title{
LA EXPLOSIÓN DEL ALQUILER Y LAS DESIGUALDADES RESIDENCIALES EN MADRID
}

\section{RENTAL EXPLOSION AND RESIDENTIAL INEQUALITIES IN MADRID}

\author{
Almudena Martínez-Del-Olmo \\ amartinezol@nebrija.es \\ Universidad Nebrija
}

\section{Resumen}

Tras el fatal desenlace que supuso el boom inmobiliario español, se ha asistido a un renacimiento de un denostado mercado de alquiler, algo insospechado dada la fuerte promoción y predilección con los que tradicionalmente ha contado la propiedad. Este cambio en el régimen de tenencia, visible sobre todo en las grandes ciudades, no se encuentra exento de dificultades, dada la escasa promoción que ha recibido el alquiler desde las políticas de vivienda y la alta especulación que opera sobre el mismo. Por este motivo, el siguiente artículo analiza el impacto del auge del mercado del alquiler sobre los comportamientos residenciales centrándose en las condiciones de acceso a la vivienda en la ciudad de Madrid. A partir de un análisis bivariado y multivariado, se argumenta como se asiste a un proceso de desigualdad residencial que se expresa mediante los crecientes problemas de acceso que afectan sobre todo a los grupos sociales más desfavorecidos lo cual repercute en sus pautas de localización.

Palabras clave: régimen de tenencia, acceso a la vivienda, localización residencial, desigualdades, Madrid

\begin{abstract}
After the disastrous outcome of the Spanish real estate boom, the last decade has witnessed a progressive revival of a highly criticized rental market, something unsuspected given the strong marketing and preferences of the homeownership sector. This tenancy change, especially visible in big cities, is not free of difficulties, given the limited promotion that the rental market has received from housing policies, and the high speculation that operates on it. For this reason, the following article examines the impact of the rental market boom on residential practices by focusing on the conditions of access to housing in the city of Madrid. Based on bivariate and multivariate analyses, it is argued that there is a growing process of residential inequality that is expressed through increasing problems of access to housing that affect especially the most disadvantaged social groups. This in turn affects location patterns of these disadvantaged groups.
\end{abstract}

Key words: housing tenure, access to housing, residential location, inequalities, Madrid 


\section{Introducción}

La crisis permanente que atraviesa la vivienda en España, se ha agudizado en la última década como producto del impacto del colapso económico y financiero sobre el sistema de vivienda, y del mismo, sobre las condiciones y comportamientos residenciales de los hogares.

La temeraria etapa vivida desde principios del nuevo siglo hasta el año 2007, en dónde la demanda de vivienda se sustentaba fuertemente en un sistema financiero que posibilitaba y animaba al endeudamiento sin límite de las familias, se tornaría en tragedia dada la incidencia directa del colapso del mercado laboral sobre la vivienda y viceversa.

Tanto los hogares que vivían en alquiler como los que accedieron a la propiedad se vieron afectados hasta tal punto que muchos de ellos fueron forzados a abandonar sus viviendas. Así, según los datos aportados por el Consejo General del Poder Judicial, el número total de lanzamientos recibidos por el Tribunal Superior de Justicia en el territorio nacional pasó de ser 27.251 en 2008 a 70.257 en 2012, alcanzándose en esta fecha el punto más álgido. La diferencia con respecto a los hogares que se hallaban en alquiler es que los hogares endeudados además de perder su casa, perdieron también las grandes sumas de ahorro invertidas y, en muchos casos, se vieron obligados a pagar la deuda restante.

De este modo, ha sido el mercado de la propiedad el que se ha visto más profundamente afectado ya que, al miedo y al prejuicio que se generó hacia este régimen de tenencia, por el riesgo a perder el dinero invertido y verse obligado a hacer frente a la deuda restante, hay que sumar el mayor impedimento que supone la creciente precariedad laboral en el acceso a la compra y las altas restricciones financieras impuestas desde la banca tras el impago de las familias y los promotores.

Como consecuencia, el resplandeciente mercado de la propiedad se ha visto fuertemente frenado y retraído en beneficio de un mercado de alquiler poco desarrollado y destinado tradicionalmente a los sectores de población más desfavorecidos (Arbaci, 2008). Su auge inesperado lleva a plantear, como objetivo principal del presente artículo, el estudio del impacto del mismo sobre las condiciones residenciales de los distintos grupos sociales, concretamente los conformados en base a la ocupación, la nacionalidad y la edad. De manera específica, se busca analizar de qué forma han evolucionado las condiciones de acceso a la vivienda en estos grupos sociales y su posible efecto en las pautas de distribución espacial.

Para la consecución de dichos objetivos se toma como ámbito de análisis espacial la ciudad de Madrid ya que, junto con Barcelona, conforman los principales escenarios del cambio en el régimen de tenencia y de la expresión de las nuevas problemáticas residenciales que conlleva.

Dado el fuerte carácter liberal que articula el sistema de provisión residencial en España y la función residual que se otorga a la vivienda social, se parte de la hipótesis de que el auge del mercado del alquiler está causando un mayor deterioro en las condiciones residenciales de los hogares más desfavorecidos, aumentando así los procesos de desigualdad residencial. Esto se manifestaría, por un lado, a través de la evolución de las condiciones de acceso a la vivienda, siendo el cálculo del esfuerzo el principal indicador al respecto, y; por otro, a través del impacto de las dinámicas espaciales del mercado del alquiler sobre las pautas de localización de los grupos más desfavorecidos económicamente (grupos ocupacionales de menor cualificación, extranjeros y jóvenes). 
La fundamentación de los objetivos y las hipótesis planteadas se apoya, por un lado, en el desarrollo de un análisis bivariado, que sirve para poner de relieve la transformación sufrida en el mercado de la vivienda en los últimos años, y por otro, en un análisis multivariado, a fin de demostrar la estrecha relación entre el cambio en el mercado de alquiler y las pautas de distribución espacial de los grupos sociales. Además, se procede a la elaboración del indicador del esfuerzo que será clave para conocer la evolución en las condiciones de acceso a la vivienda.

A continuación, el artículo examina, tras la presente Introducción, el debate teórico que fundamenta la existencia y las características del sistema de vivienda español, claves para comprender posteriormente las dinámicas residenciales vividas en la Ciudad de Madrid. A continuación, el tercer apartado, examina las causas que han conducido al boom en el mercado del alquiler, prestando especial atención tanto a la influencia que se ejerce desde el lado de la demanda de vivienda habitual como desde el lado de la inversión. En el cuarto apartado se estudia el impacto del auge del mercado de alquiler en las condiciones residenciales de los grupos sociales, concretamente las referidas al acceso a la vivienda y a los procesos de distribución espacial. Por último, en la conclusión, se exponen las principales problemáticas residenciales actuales derivadas de la acción del mercado de la vivienda en la ciudad de Madrid.

\section{La articulación del sistema de vivienda en España como marco de comprensión del contexto residencial madrileño}

En España, como fruto de la distribución de competencias establecida en la Constitución Española de 1978 y en los estatutos de autonomía de las comunidades autónomas, el gobierno central procedió a la descentralización de la gestión de la vivienda social y los planes de vivienda en favor de los ayuntamientos o gobiernos autonómicos. Sin embargo y a pesar de que se pueden establecer distinciones entre las distintas comunidades autónomas (Echaves, 2017), éstas se encuentran en buena medida condicionadas por las medidas del Estado en materia de fiscalidad, inversión, normativas y diseño de planes de actuación (Leal y Martínez, 2016), por lo que no dejan de estar inmersas en un mismo contexto. Es por este motivo por el que, la comprensión del contexto residencial madrileño y sus actuales problemáticas pasa por el conocimiento del sistema de vivienda estatal en el que se integra, lo que a su vez implica la adopción de una perspectiva comparada internacional que aporte luz con respecto al posicionamiento que adoptan otra serie de países. En este sentido, los modelos de bienestar han servido de marco fundamental para reflexionar y clarificar el modo en el que se articula la vivienda y el papel que juega ésta en cada sociedad. Como punto de partida, es conocida la influyente obra de Esping-Andersen (1990) que sostiene como, en base a la forma en la que se articulan las dimensiones del estado de bienestar referidas al grado de desmercantilización, estratificación social y la relación con el mercado, en Europa coexisten tres tipos ideales de regímenes de bienestar: el liberal, el conservador y el social-democrático. A la hora de establecer estas tipologías, la desconsideración del papel clave que juegan otras dimensiones del bienestar, además del estado, y la ausencia de la vivienda como un objeto de su análisis, generó numerosas críticas (Allen, 2006; Castles, y Ferrera, 1996), lo que a su vez sirvió como fuente de inspiración fundamental para la mayoría de los estudios de vivienda. 
Al respecto, Jim Kemeny es el autor que mejor representa la reacción crítica a la indiferencia científica hacia la vivienda como dimensión del bienestar. A través de "Housing and Social Theory" (1992), Kemeny sienta las bases teóricas que le conducen a la formulación de una sociología de la residencia en base a la cual sostiene que la trascendencia social de la vivienda pasa necesariamente por su integración dentro del sistema de bienestar. Al analizar los mecanismos de provisión residencial, Kemeny incorpora tanto la importancia que juega el estado como el mercado y otras instituciones, ofreciendo así un marco interpretativo del bienestar más completo que el de Esping Andersen. El modo en el que interfieren los distintos agentes implicados en la provisión de vivienda, así como las funciones adoptadas por cada uno de ellos le permite identificar distintos sistemas de vivienda los cuales desarrollará más en profundidad en su obra más célebre "From Public Housing to the Social Market" (1995), en la que analiza la relevancia que juegan las formas de tenencia en el bienestar de los hogares, definiendo a partir ellas la existencia de dos sistemas de vivienda distintos. Por un lado, diferencia los sistemas de alquiler dual, en donde la provisión de vivienda social viene exclusivamente de la mano del estado y se restringe a los sectores de población más desfavorecidos, protegiéndose así de la competencia al mercado privado en donde el sector del alquiler resulta costoso, minoritario y poco atractivo frente a la propiedad que obtiene un gran apoyo desde las políticas de vivienda y es en consecuencia el régimen de tenencia predominante. Los países angloparlantes (Gran Bretaña, Irlanda, EE.UU. y Australia) y algunos escandinavos (Noruega, Finlandia e Islandia) se integrarían dentro de este modelo. Por otro lado, distingue los sistemas de alquiler unitario en donde la política de vivienda garantiza la competitividad entre el sector social y privado del alquiler provocando que la propiedad adquiera un rol secundario puesto que la efectividad y predominancia del mercado del alquiler ofrece alternativas más sugerentes dentro de un sistema universalista en el que la intervención del Estado se dirige a todos los ciudadanos sin distinción de renta o de condición social. Identifica varios países dentro de este modelo y los divide en función del nivel de desarrollo que presente su sector social de alquiler: los Países Bajos presentarían el mayor nivel de vivienda social, mientras que en países como Suecia o Dinamarca habría un equilibrio y en Alemania y Suiza predominaría el alquiler privado.

El problema al planteamiento teórico de Kemeny es que los sistemas de tenencia resultantes acaban limitándose a las formas de organización residencial de los países que analiza, en su mayoría angloparlantes y escandinavos. Esta simplificación provoca que, cuando se intenta aplicar su teoría a otros contextos residenciales, su encaje resulte problemático tal y como constata Leal (2005:75) cuando afirma que, pese a que el sistema español pueda ser integrado dentro de los sistemas de tenencia dual, la preponderancia de la propiedad dentro del propio mercado de vivienda social (Viviendas de Protección Oficial) implica un desajuste con respecto a las tipologías diseñadas por Kemeny en tanto que contemplan al alquiler como la única forma contractual posible dentro del sector de vivienda desmercantilizado.

Sin prescindir del papel decisivo de los sistemas de tenencia a la hora de establecer familias de bienestar, Barlow y Duncan (1994) añaden otra perspectiva indispensable al evaluar las formas de promoción residencial y provisión del suelo de forma que, en un sistema liberal, con Inglaterra como paradigma, la promoción residencial es de tipo especulativo y la provisión de suelo gestionada por los promotores privados. Así, el acceso a la vivienda queda sometido a las fluctuaciones del mercado siendo residual la intervención del estado. En el sistema corporativista, con Francia como arquetipo, se aplica una regulación en los costes del suelo y la vivienda de manera 
que el acceso a la misma queda más protegido. El sistema social-democrático, representado por Suecia, se caracteriza por una promoción de vivienda y una gestión del suelo desmercantilizada con una fuerte restricción hacia la obtención de beneficios por lo que las problemáticas de acceso a la vivienda son escasas. El sistema rudimentario, sin ningún país identificado como prototípico, se rige por una promoción de vivienda especulativa y una gestión privada del suelo lo que les convierte en proclives a presentar problemas de acceso a la vivienda que afectan sobre todo a los grupos más vulnerables económicamente.

Los poderosos esquemas interpretativos de Esping-Andersen, Kemeny y Barlow y Duncan, sirvieron como fundamento a una serie de autores (Allen et al, 2004) para identificar, de forma concluyente, un sistema residencial propio de los países del Sur de Europa, en donde se integra España, enriqueciendo así el espectro teórico necesario para comprender los múltiples procesos residenciales que acontecen y abordar de forma más eficaz las políticas de bienestar. Este sistema ha sido concebido por estar basado en un régimen de bienestar distinto, lo que supone la identificación de otra alternativa de bienestar a las originalmente esbozadas por Esping-Andersen (1990). Sus características distintivas se fundamentaban en una configuración de un sistema de bienestar en la que el Estado tenía poca participación en la provisión de subsidios y servicios y también en la regulación de las actividades de mercado, delegando así a la solidaridad familiar y a la sociedad civil un número de funciones que las entidades públicas tendían a asumir en otros países europeos. Por lo tanto, uno de los pilares de este sistema residencial fue que la familia actuaba para proporcionar el acceso a la vivienda a sus miembros, con el apoyo disponible en cada caso.

Dentro de dicho sistema el caso español constituye un referente principal caracterizado tradicionalmente (Allen et al, 2004) por tener una gran proporción de hogares viviendo en propiedad en detrimento de un sector del alquiler exiguo, informal y en mal estado. Al mismo tiempo, se constataba cómo la convivencia dentro del núcleo familiar se prolongaba más en el tiempo con respecto al resto de los países europeos, debido en buena medida al retraso de la emancipación de los jóvenes. Así, las familias eran empujadas a asumir la permanencia de sus hijos en sus hogares hasta las edades posteriores, debido a los problemas que afectaron tanto al mercado laboral como al residencial (Fernández Cordón y Leal, 2014).

También se identificó una forma diferente de producción de viviendas, en la que gran parte del beneficio de los promotores provenía del proceso de revalorización del suelo a diferencia con otros modelos en los que el beneficio provenía de la construcción. Por último, se daban también una serie de características diferenciales en términos de política de vivienda, con un bajo porcentaje de viviendas de alquiler social, una inversión pública más escasa en vivienda en relación al PIB y una canalización clientelar de los subsidios para el acceso a la vivienda que se extiende a las clases medias.

La intervención pública sobre la vivienda se basó, en gran parte, en acciones indirectas en las que se dio prioridad a las medidas socialmente regresivas que favorecían a las clases medias, como son la promoción de la deducción fiscal y el mantenimiento de la escasez de vivienda social de alquiler.

Este sistema de vivienda refleja hoy algunos cambios, sobre todo el concerniente al régimen de tenencia por el ascenso imprevisto del mercado de alquiler, cuya explicación e impacto sobre las condiciones residenciales de la población son objeto de estudio a continuación en base al contexto madrileño. 


\section{El inesperado boom del mercado del alquiler y sus causas}

El ocaso vivido en el consagrado mercado de la propiedad, tras el impacto de la crisis inmobiliaria, económica y financiera, ha servido para poner en el punto de mira al mercado del alquiler de forma que se asiste a unboom que responde a los cambios sufridos en la intensidad y en la forma en la que se configura la demanda de vivienda bajo esta forma contractual, siendo así el principal objetivo de este apartado su evaluación a través del caso madrileño.

\subsection{Los cambios recientes del comportamiento residencial en favor del alquiler}

El aumento de la demanda del alquiler y su repercusión sobre el número de hogares que viven bajo este régimen de tenencia era constatado ya en el periodo del boom inmobiliario de principios del siglo XXI. El crecimiento de las necesidades residenciales derivadas de los fuertes cambios sociodemográficos, que implicaban el aumento de una población inmigrante extranjera recién llegada y en condiciones precarias, así como el ascenso de unos nuevos modelos familiares y laborales condujeron a un ascenso progresivo del alquiler, a lo que hay que añadir la tendencia positiva que experimentaba la formación de hogares jóvenes (Módenes y López-Colás, 2014).

Sin embargo, en términos relativos, el aumento del alquiler en detrimento de la propiedad, surge como consecuencia directa del fatal desenlace que supuso el boom inmobiliario basado en la compra de vivienda. De esta forma, en los últimos años se ha asistido a un intenso renacimiento de un denostado mercado de alquiler, algo insospechado dado el fuerte asentamiento y predilección con los que tradicionalmente ha contado el mercado de la propiedad en nuestra sociedad. Tal y como muestra el gráfico 1, según la Encuesta de Condiciones de Vida, en la Comunidad de Madrid en el año 2007 , un $80,7 \%$ de los hogares vivía en propiedad, alcanzándose uno de los máximos apogeos de este régimen de tenencia que desciende hasta un $73 \%$ en beneficio del alquiler en el año 2017. De esta forma, la presencia del alquiler en los hogares pasa de representar un $17,3 \%$ a un $24,3 \%$.

Gráfico 1. Evolución de la distribución de los hogares en las distintas formas de tenencia en la Comunidad de Madrid (2004-2017)

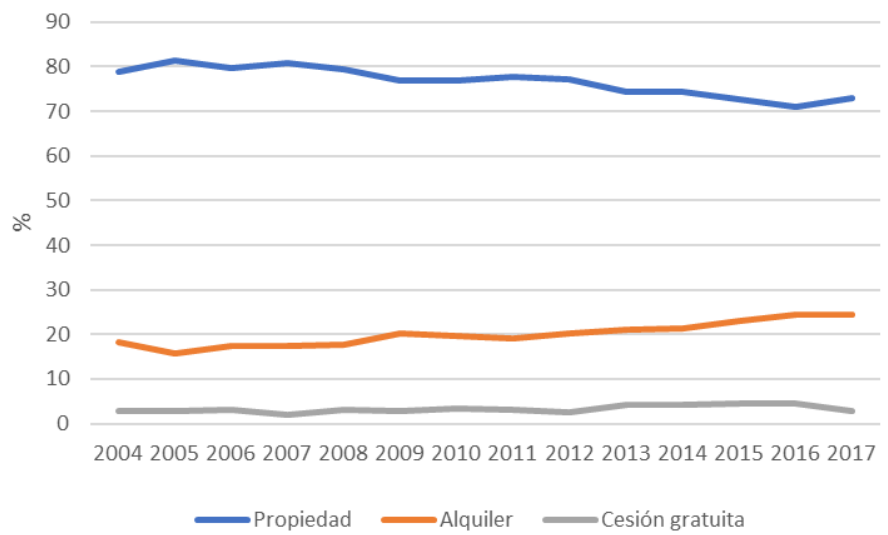

Fuente: Encuesta de Condiciones de Vida

Las implicaciones de la crisis sobre este cambio decisivo en el comportamiento residencial, lejos de responder a una única causa es el reflejo de varios desencadenantes interrelacionados y conectados en el tiempo. 
Por un lado, la creciente desconfianza hacia la compra se alza como una de las palancas directas del alquiler como reacción a las situaciones críticas residenciales vividas por aquellos hogares que, incapaces de hacer frente los pagos de la hipoteca, se vieron no sólo obligados a abandonar sus viviendas sino también a hacer frente a la deuda restante. De esta forma, en la época del boom inmobiliario, el acceso a la vivienda en propiedad implicaba la asunción de un fuerte esfuerzo y compromiso hipotecario que mermaba las condiciones económicas y vitales de los hogares. Aun así, pese a los riesgos inherentes que entrañaba, se prefería mayoritariamente la compra por las ventajas que suponía frente a un mercado del alquiler exiguo, costoso, informal y deteriorado. La compra era el equivalente a la seguridad, la autonomía y el ahorro mientras que el alquiler simbolizaba más el derroche, la precariedad y la inseguridad por lo que éste se percibía como una opción transitoria hacia la propiedad y de alojamiento para los grupos sociales más desfavorecidos. Sin embargo, el estallido de la crisis introdujo un cambio de perspectiva que favorecería el crecimiento del alquiler, sobre todo en los años inmediatos al estallido de la crisis, ya que a pesar de que los desahucios en los arrendamientos sean normalmente superiores con respecto a los que se producen a través de una ejecución hipotecaria, el alquiler se alzaba como un régimen de tenencia que no entrañaba compromisos y riesgos económicos a largo plazo y que permitía adoptar estrategias residenciales, como la de vivir en el centro o la de compartir piso, que suponía un ahorro en los gastos de la vivienda.

Al mismo tiempo, acompañando a los factores ligados más a las preferencias, desencadenados por las convulsiones sufridas en un mercado de vivienda regido por un sistema liberal-familialista, hay que considerar la influencia de los factores de constricción ya que, con el estallido de la crisis, el acceso a la compra se hizo todavía más complicado puesto que si bien los intereses hipotecarios y los precios de la vivienda bajaron progresivamente, la falta de financiación, el endurecimiento en las condiciones para la concesión de hipotecas y la supresión definitiva de la desgravación fiscal por vivienda habitual en el año 2013 empujaron a los hogares hacia el alquiler (Pareja-Eastway y Sánchez-Martínez, 2011). Cierto es que, desde 2013, se aprecia un ascenso en el volumen y el importe de las hipotecas concedidas, sin embargo, la recuperación acontece a un ritmo suave, incapaz todavía de respaldar una entrada normalizada de los demandantes al mercado, a los que se les exige de media el aporte de más del 45\% del valor de la vivienda (Taltavull, P. 2017).

De esta forma, la única salida residencial para buena parte de los hogares demandantes de primera vivienda ha sido el alquiler, tendencia que además se ha visto tremendamente reforzada por la incidencia simultánea que, de cara al acceso a la vivienda, juega también la situación laboral de los hogares no pudiéndose ignorar que el efecto del crecimiento de la precariedad laboral, derivado del aumento de la eventualidad, la parcialidad y la devaluación salarial (Lorente y Guamán, 2018), ha supuesto también un fuerte impedimento para aquellos hogares que, aun queriendo acceder a una vivienda en propiedad, se ven ahora destinados a alquilar como única alternativa habitacional.

\subsection{El papel de la inversión en el alquiler de vivienda habitual}

El giro de los hogares hacia la vivienda en alquiler y la contención que vive todavía el sector de la propiedad ha servido a su vez para poner el foco inversor en el arrendamiento para vivienda habitual ya que, consciente de la insuficiente oferta que tradicionalmente ha caracterizado al mercado de alquiler éste era susceptible de convertirse en una importante fuente de obtención de rentabilidades y de hecho así ha sido. Tal como se puede observar en el siguiente gráfico, el rendimiento bruto de la rentabilidad del alquiler no ha dejado de crecer, superando a la que se obtiene de los bonos del estado a 10 años. 
Gráfico 2. Evolución de la rentabilidad bruta por alquiler en el Municipio de Madrid y del interés de los bonos del estado a 10 años

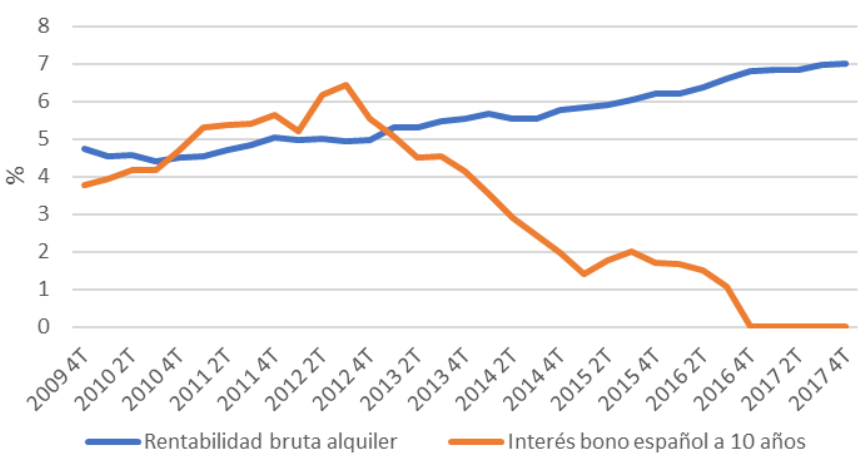

Fuente: Idealista, Ministerio de Fomento e INE.

Esta ventana de oportunidad justifica que la inversión en alquiler, por parte de particulares pero también por parte de empresas, no haya dejado de crecer en los últimos años marcando así un cambio de tendencia sin precedentes. En este contexto y según datos registrados en el portal inmobiliario de Idealista, Madrid fue la Comunidad Autónoma en la que hubo un mayor número de viviendas de alquiler en el mercado en 2017 (195.507), habiendo experimentado un crecimiento relativo con respecto al año anterior del 6\%.

Cabría pensar en el apogeo de la inversión en el alquiler de vivienda habitual como factor de presión a la baja en los precios. Sin embargo, existen varias causas por las que no ha sido así. Por un lado, pese a que a nivel nacional, las sociedades inmobiliarias, concretamente las SOCIMIS, puedan controlar un porcentaje mínimo del total de viviendas en alquiler, este porcentaje es susceptible de subir en las grandes ciudades como Madrid, en cuya provincia se concentra de hecho la mayor parte de sus viviendas (47\%), cuestión que inevitablemente favorece un dominio por su parte a la hora de fijar el precio de los alquileres, en función de sus intereses, lo que contribuye a su alza y así también al crecimiento de la rentabilidad (véase gráfico 3).

\section{Gráfico 3. Viviendas en alquiler propiedad de SOCIMIS por provincias, 2018}

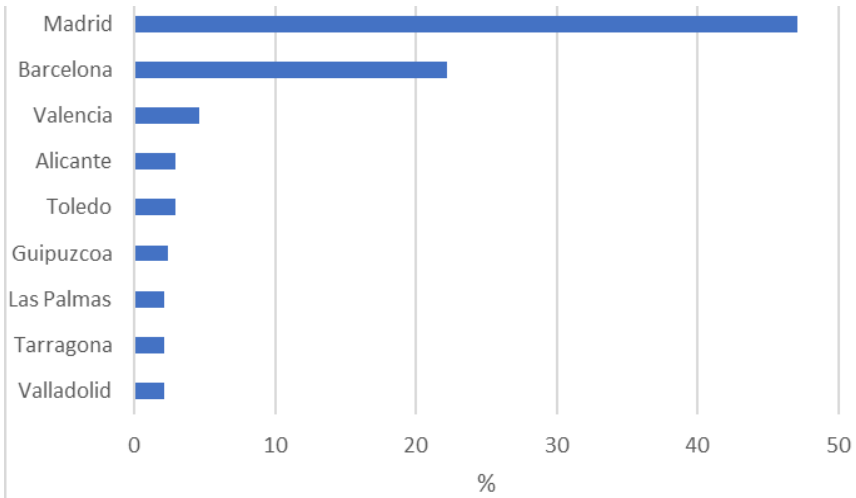

Fuente: Mercado Alternativo Bursátil, en eldiario.es

Al mismo tiempo, pese a que la oferta haya podido crecer, la nueva ley de arrendamientos urbanos de 2013 ha contribuido también a reforzar la tendencia al alza en los 
precios a través de la reducción del periodo del alquiler mínimo de 5 a 3 años ya que se facilita una actualización de las rentas más rápida. Por un último, la posible oferta creciente que podría derivarse del crecimiento de la inversión y su posible efecto a la baja en los precios se ve contrarrestada, como se analiza en el siguiente epígrafe, por el auge de los alquileres turísticos.

\subsection{El impacto añadido de los alquileres turísticos}

Al aumento de la demanda de alquiler de la vivienda habitual (tanto por necesidad como por inversión), como factor explicativo de la escalada de precios de este mercado hay que sumar el impacto que, sobre una oferta escasamente desarrollada, está teniendo el auge del negocio de los arrendamientos turísticos.

El fuerte desarrollo turístico y el aumento del número de viajeros ha conducido al impulso de nuevas formas de alojamiento que se ven favorecidas e incluso justificadas bajo el paraguas que ofrecen las conocidas plataformas como Airb\&b. Sin embargo, dichas plataformas, que en un principio se presentaban como promotoras del surgimiento de una forma de economía colaborativa, que servía a los pequeños propietarios como forma de conseguir unos ingresos extra, se han convertido en un fuerte vehículo de inversión, que sitúa al alquiler turísticocomo un negocio altamente rentable y especulativo en manos de grandes profesionales y propietarios en busca de un "rent gap" (Gil, J. y Sequera, J. 2018)

La escasa regulación fiscal existente en esta materia, la ausencia de un compromiso de larga duración con el inquilino, junto con las altas rentabilidades que se obtienen se han convertido en palancas fundamentales para el crecimiento de este sector lo que conlleva dos implicaciones fundamentales en el mercado de alquiler de vivienda habitual. Por un lado, induce a un ajuste en la oferta de alquiler de vivienda habitual ya que la apuesta por la rentabilidad de este sector acontece no sólo a través de la reconversión de la oferta de alquiler habitual ya existente a otra turística sino también a través de la disminución de la potencial oferta nueva que podría ser destinada a vivienda habitual. Por otro lado, supone un claro aliciente para la subida de precios, no sólo por el efecto reductor que ejerce este negocio sobre la oferta de vivienda habitual en alquiler sino también por el efecto de arrastre que generan las rentas de los pisos turísticos (Cabrerizo et al. 2016; Díez, 2017).

\section{Los efectos del auge del mercado de alquiler en el compor- tamiento residencial}

Una vez puesto de manifiesto el nuevo contexto residencial que se dibuja en los últimos años, a continuación, se establece una aproximación a la realidad residencial que atraviesan los distintos grupos sociales en la ciudad de Madrid, analizándose los comportamientos y los posibles procesos de desigualdad en base a las condiciones de acceso a la vivienda y su efecto en las pautas de localización espacial.

\subsection{El acceso a la vivienda, un obstáculo creciente entre los grupos sociales más vulnerables}

La ausencia histórica de una apuesta pública decidida por el desarrollo de un mercado del alquiler, tanto social como libre, en contraposición a la fuerte promoción que ha recibido la propiedad, ha contribuido de forma estructural y decisiva a la existencia de un stock de vivienda en alquiler exiguo y precario de manera que, en el contexto actual, en el que de forma inesperada los hogares se vuelcan hacia este régimen de 
tenencia, se asiste a una presión sobre una oferta de por sí escasa que conduce a un aumento de precios sin precedentes. Dicho aumento, se ve además impulsado, como se ha indicado, por el tipo de inversión en el sector y por el auge de los alquileres turísticos que contribuyen a mermar y encarecer la oferta, generándose así un verdadero problema social (Rodríguez, J. 2017).

Todas las grandes ciudades españolas se han visto afectadas por este boom del alquiler, pero Madrid y Barcelona son las que representan mejor el alcance del fenómeno de manera que en el cuarto trimestre de 2017 el precio del alquiler llegaba a los $15,5 € / \mathrm{m} 2$ y los $17,5 € / \mathrm{m} 2$ respectivamente.

Gráfico 4. Evolución del precio del alquiler $(€ / \mathrm{m} 2)$ en las principales ciudades españolas

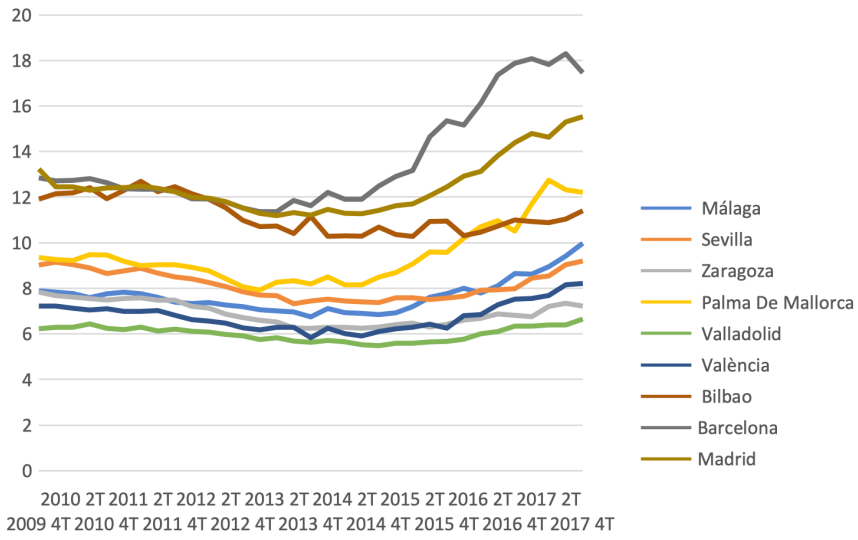

Fuente: Idealista

Tal como se puede apreciar en el gráfico 5, desde el periodo 2013-2014, el alquiler en Madrid ha experimentado un crecimiento relativo constante que ha excedido al registrado en la propiedad, a excepción del último periodo correspondiente a 2016-2017, en el que se aprecia una equiparación entre ambos tipos de tenencia.

Gráfico 5. Evolución relativa de los precios del alquiler y la propiedad en la ciudad de Madrid

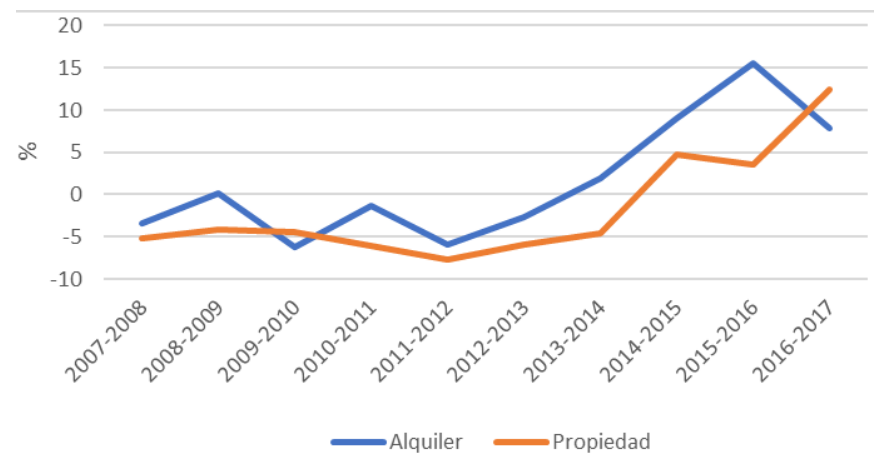

Fuente: Idealista

El preocupante escenario que se deriva de tal contexto, unido a la persistencia de la precariedad laboral, convierte al análisis de las condiciones de acceso a la vivienda en fundamental dada la influencia primaria que ejerce sobre el cumplimiento del derecho a una vivienda digna y adecuada, tal y como se recoge en el artículo 47 de la Constitución Española y en la Declaración Universal de los Derechos Humanos de 1948. 
En este sentido, el esfuerzo de acceso a la vivienda, entendido como el porcentaje del salario mensual que se precisa para hacer frente a los pagos de la vivienda, ya sean procedentes de la renta del alquiler o de la hipoteca, si la vivienda es comprada, se presenta como uno de los indicadores más fundamentales a la hora de medir los cambios y las posibles dificultades en las condiciones de acceso a la vivienda de la población y en los procesos de desigualdad por lo que su análisis resulta en este caso indispensable.

En el contexto de la región madrileña, la estimación del esfuerzo medio de acceso a la vivienda en alquiler dibuja una tendencia general creciente que obedece al aumento desproporcionado de los precios de las rentas en relación a la evolución registrada por los salarios. Tomando de partida el año 2013, por ser en el que los precios del alquiler comienzan a repuntar (véase gráfico 5), y el año 2016, por ser el más reciente para el que se dispone de datos salariales desagregados por grupos sociales, se comprueba que el esfuerzo de acceso ha aumentado de media 10 puntos porcentuales, pasando de un $36 \%$ a un $46 \%$. En general, se considera que el esfuerzo de acceso nunca debería sobrepasar el $30 \%$ de los ingresos del hogar y, aunque se analizan datos salariales que se refieren, en este caso, a individuos y no a hogares, la tendencia ascendente no deja de ser alarmante y más si se tiene en cuenta que, en la región de Madrid, los hogares unipersonales y monoparentales suponían ya en 2016 un 36,5\% del total de hogares, según la Encuesta Continua de Hogares.

Por otra parte, esta tendencia no se traslada de manera uniforme a los distintos grupos sociales sino que, tal como se puede apreciar a través de los siguientes gráficos $(6,7$ y 8), los más jóvenes, los extranjeros y las ocupaciones de menor cualificación no sólo constituyen los grupos sociales que mayor esfuerzo deben realizar de por sí, sino que además son los que sufren en mayor medida el endurecimiento de éste, constatándose, así, que se asiste también a un aumento de la desigualdad residencial desde abajo. Mientras que los individuos menores de 25 años, o los situados en el intervalo de 25 a 34 años, han visto crecer su esfuerzo en 11 y 14 puntos porcentuales respectivamente, el resto de grupos de edad no supera los 10 puntos porcentuales. En función de la nacionalidad, los extranjeros habrían experimentado un aumento de su esfuerzo de 14 puntos porcentuales en contraste con los 10 puntos porcentuales de los españoles. Por ocupación, las categorías de menor cualificación habrían registrado un crecimiento del esfuerzo de 18 puntos porcentuales en comparación con la categoría media o alta en las que el crecimiento es de 13 y 7 puntos porcentuales.

Gráfico 6. Esfuerzo de acceso a la vivienda en alquiler según la edad en Madrid.2013-2016

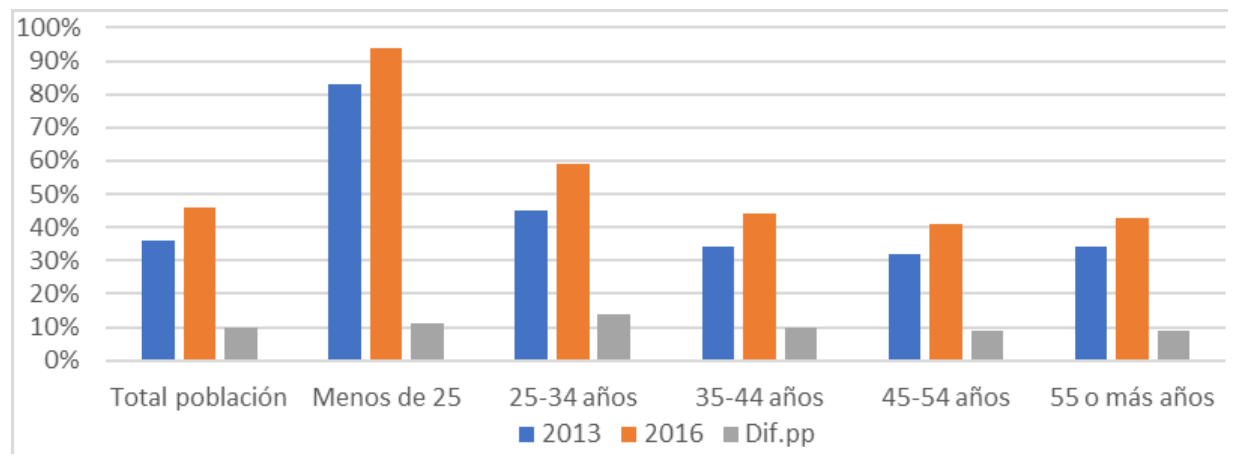

Fuente: Encuesta de estructura salarial (para datos sobre salarios) e Idealista (para datos de precios de alquiler). 
Gráfico 7. Esfuerzo de acceso a la vivienda en alquiler según la nacionalidad en Madrid.2013-2016

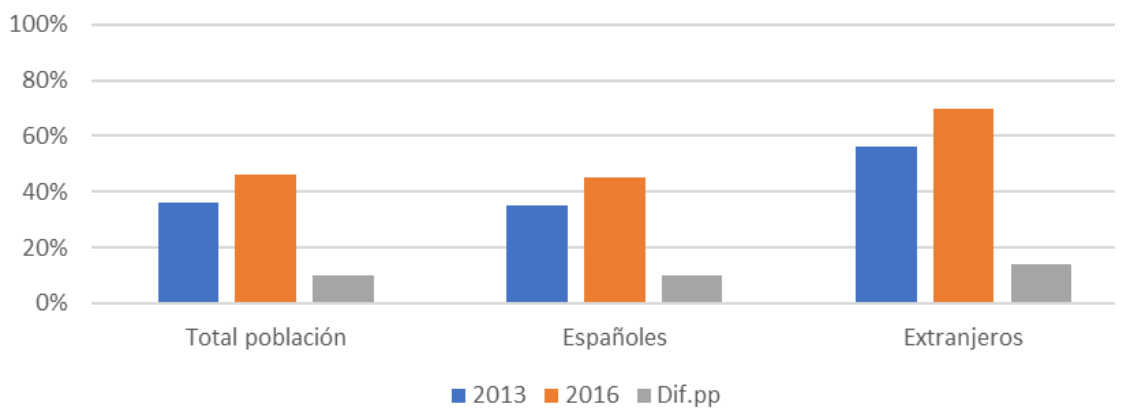

Fuente: Encuesta de estructura salarial e Idealista.

Gráfico 8. Esfuerzo de acceso a la vivienda en alquiler según la ocupación en Madrid.2013-2016

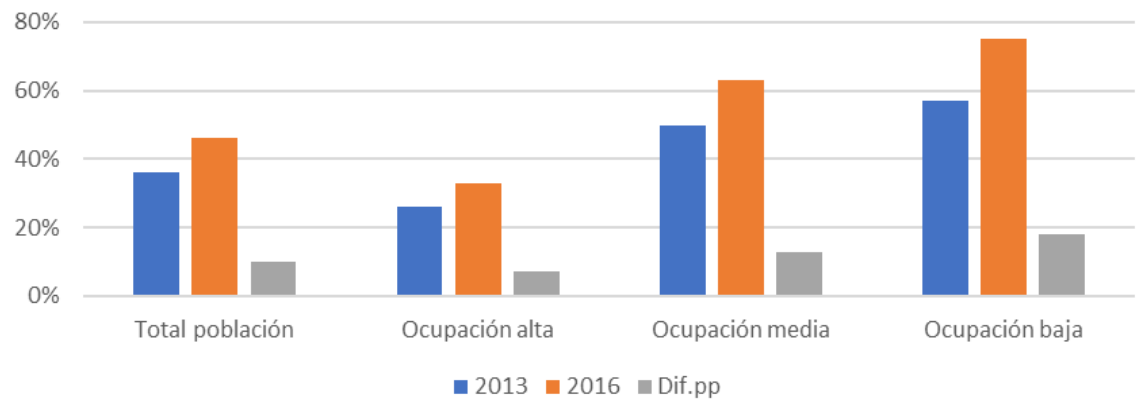

Fuente: Encuesta de estructura salarial e Idealista.

Se debe considerar, además, que las mayores dificultades de acceso a la vivienda que experimentan los grupos sociales más desfavorecidos económicamente no sólo se ven agravadas por el mayor crecimiento del esfuerzo de acceso al alquiler, sino también y, sobre todo, por su gran dependencia hacia esta forma contractual a la hora se satisfacer sus necesidades residenciales. Las exigencias económicas, laborales e incluso legales (en el caso de los extranjeros) que requiere el acceso a la propiedad ha hecho que el alquiler haya funcionado tradicionalmente como la principal vía de acceso a la vivienda para estos grupos, siendo por este motivo calificado como el equivalente a la vivienda social de otros países europeos (Pareja-Eastway y Sánchez-Martínez, 2016) , lo cual, en este momento, no deja de ser controvertido dado el especial endurecimiento en el acceso al mismo y su efecto perverso sobre el resto de condiciones residenciales.

De hecho, con independencia de las posibles preferencias crecientes hacia el arrendamiento de una vivienda, el aumento de la precariedad laboral y el endurecimiento de las condiciones de acceso a la propiedad no habrían sino alimentado aún más esta dependencia hacia el alquiler en el caso de los grupos sociales más vulnerables. Tal como reflejan los gráficos 9 y 10, el aumento del alquiler se habría acentuado de forma general en el conjunto de la población, pero especialmente en los grupos más vulnerables, desde los años posteriores al estallido de la burbuja en 2007. 
Gráfico 9. Evolución del porcentaje de hogares que viven en régimen de alquiler a precios de mercado en función de la edad en España

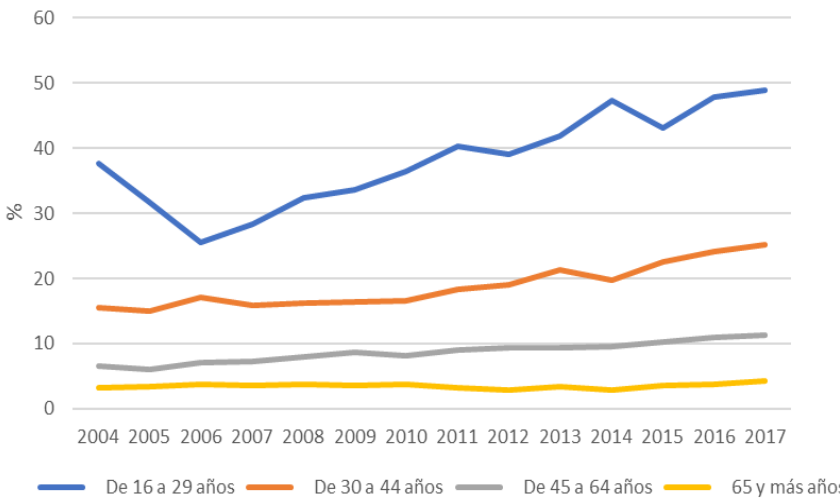

Fuente: Encuesta de Condiciones de Vida

Gráfico 10. Evolución del porcentaje de hogares que viven en régimen de alquiler a precios de mercado en función de la nacionalidad en España

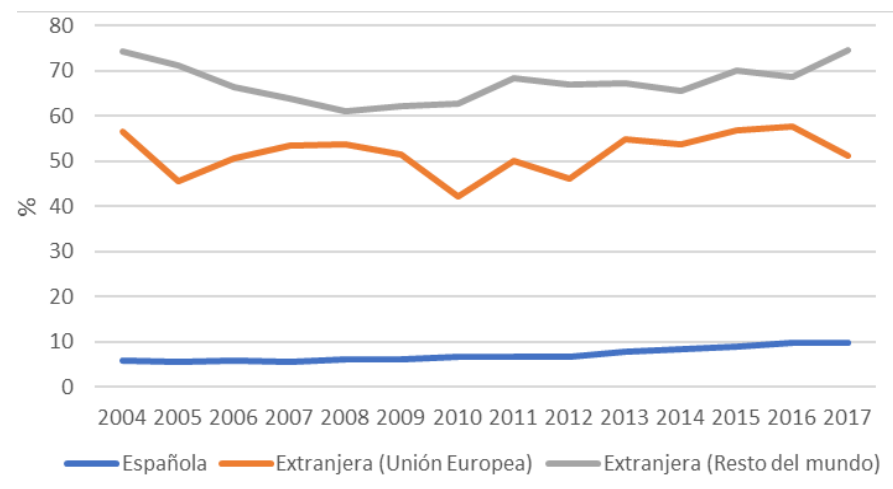

Fuente: Encuesta de Condiciones de Vida

Cabría pensar que las crecientes facilidades hipotecarias podrían conducir de nuevo hacia una recuperación progresiva de los márgenes que registraba la propiedad entre los grupos más vulnerables antes del estallido de la burbuja. Además, a diferencia del mercado de alquiler, el esfuerzo de acceso a este régimen de tenencia ha tendido a disminuir o aumentar en menor medida. Sin embargo, pese a que el mercado de la compra no haya estado sometido a las mismas presiones al alza, el acceso a la propiedad para los grupos más vulnerables no deja de ser mucho más complicado que el que presenta el mercado de alquiler ya que cuestiones como la falta de ahorro y la mayor precariedad e inestabilidad económica y laboral les afectan en mayor medida evitando que la compra se consolide como una alternativa real.

Por tanto, se está ante un escenario en el que, mientras el acceso a la propiedad sigue siendo inalcanzable para estos grupos vulnerables, el acceso al alquiler, del que dependen cada vez más, no ha hecho más que complicarse de forma que:

El aumento en el esfuerzo de acceso al alquiler en los grupos más vulnerables no sólo revela un empeoramiento en sus condiciones de acceso a la vivienda sino también una agudización de los procesos de desigualdad residencial ya que, la tenencia 
al alza en este indicador les afecta en mayor medida. Por tanto, se constata una agudización de los procesos de desigualdad residencial desde abajo.

Se asiste a una merma en las posibilidades residenciales que afectan sobre todo a grupos sociales más vulnerables, favoreciéndose el crecimiento o surgimiento de nuevas formas de precariedad residencial como el hacinamiento.

\subsection{El distrito centro como eje articulador de las nuevas desigualdades resi- denciales en el espacio}

La transformación en el mercado del alquiler no sólo supone una alteración preocupante en las condiciones de acceso a la vivienda que impactan sobre los hogares, sobre todo los más vulnerables, sino también una variación de la dimensión espacial del mercado residencial que conduce inevitablemente hacia la transformación de los procesos de desigualdad social en el espacio. De este modo, el mercado de vivienda actúa como elemento catalizador fundamental de la distribución de la población de acuerdo con sus características sociales, sus ingresos y su patrimonio, de forma que la comprensión de los procesos segregativos en la ciudad pasa inevitablemente por la comprensión del modo en el que se articula el mercado de vivienda y de cómo se establece la diferenciación de los precios de las viviendas (Leal, 2002).

¿De qué modo se ha transformado el espacio residencial en Madrid? A la hora de plantear esta cuestión hay que partir del hecho de que el alcance de un profundo conocimiento respecto al funcionamiento concreto del mercado del alquiler en el espacio se ve bastante limitado dada la escasa y precaria información pública existente, lo que resulta paradójico dada la importancia creciente del sector y las problemáticas surgidas. Las fuentes principales que arrojan luz sobre el número de hogares en alquiler son los censos, de periodicidad decenal; y las encuestas de hogares y de Condiciones de Vida, cuya información no se desagrega más allá del ámbito regional. Tal como señala Rodríguez, J. (2018) "la situación estadística del mercado del alquiler en España resulta, pues, a todas luces insatisfactoria”, y por tanto preocupante, dada además la tendencia a la externalización de los datos hacia entes privados e interesados que podrían afectar a la política de vivienda (Rodríguez, R. y Espinoza, M. 2018). Cuando lo que se busca es además la realización de un análisis a nivel inframunicipal, a la ausencia de datos actualizados y fiables hay que sumar los bajos niveles de desagregación espacial de la información que implican un desconocimiento de las dinámicas concretas existentes en el espacio. No obstante, en función los datos disponibles, a continuación, se efectúa un análisis multivariable de conglomerados, basado en el procedimiento de $\mathrm{K}$ medias, que pretende ser una aproximación a los cambios territoriales sufridos en los últimos años en el mercado de vivienda de alquiler en la ciudad de Madrid, tomando como casos de referencia sus 21 distritos. Siguiendo los criterios de disponibilidad y actualización de los datos, se procede a una desagregación por distritos de los siguientes indicadores:

Tabla 1. Relación de indicadores contemplados en el análisis de conglomerados

\begin{tabular}{|c|c|c|}
\hline INDICADORES & FUENTE DE INFORMACIÓN & AÑOS \\
\hline $\begin{array}{c}\text { Precio de la vivienda en alquiler } \\
\begin{array}{c}\text { Incremento de precios de la vivienda en } \\
\text { alquiler (€/m2) }\end{array}\end{array}$ & Idealista.com & 2013 \\
\hline $\begin{array}{c}\text { Porcentaje de vivienda en alquiler (resi- } \\
\text { dencial habitual) }\end{array}$ & Censo & $2013-2016$ \\
\hline
\end{tabular}


De este modo, tras proceder a la tipificación de los indicadores, dado el distinto nivel de medición que presentaban, y obedeciendo a criterios lógicos desde un punto de vista estadístico (Cea D'Ancona, 2002), se establecieron cuatro conglomerados cuyos resultados, ya destipificados a fin de poder ser interpretados, se reflejan a continuación:

Tabla 2. Resultados del análisis de conglomerados

\begin{tabular}{|c|c|c|c|c|}
\hline \multirow{2}{*}{ Indicadores } & \multicolumn{3}{|c|}{ Conglomerados (valores destipificados) } \\
\cline { 2 - 5 } & $\begin{array}{c}\text { Clus- } \\
\text { ter 1 }\end{array}$ & Cluster 2 & Cluster 3 & Cluster 4 \\
\hline Distritos & Centro & $\begin{array}{c}\text { Arganzuela, } \\
\text { Chamartín, } \\
\text { Chamberí, } \\
\text { Moncloa, Retiro, } \\
\text { Salamanca, } \\
\text { Tetuán }\end{array}$ & $\begin{array}{c}\text { Barajas, Hor- } \\
\text { taleza, Usera, } \\
\text { Villa de Vallecas }\end{array}$ & $\begin{array}{c}\text { Carabanchel, Ciudad } \\
\text { Lineal, Fuencarral, La- } \\
\text { tina, Moratalaz, Puente } \\
\text { de Vallecas, San Blas, } \\
\text { Vicálvaro, Villaverde }\end{array}$ \\
\hline $\begin{array}{c}\text { Precio alquiler 2013 } \\
(€ / \text { m2) }\end{array}$ & 13,4 & 11,9 & 9,7 & 8,9 \\
\hline $\begin{array}{c}\text { Incremento relativo } \\
\text { del precio del alqui- } \\
\text { ler 2013-2016 (\%) }\end{array}$ & 32,2 & 25,9 & 7,9 & 16,7 \\
\hline $\begin{array}{c}\text { Porcentaje de } \\
\text { vivienda en alquiler } \\
2011 \text { (\%) }\end{array}$ & 39,6 & 23,3 & 17,9 & 15,6 \\
\hline
\end{tabular}

- El primer conglomerado, se encuentra conformado exclusivamente por el distrito centro ya que la intensidad del cambio que sufre en su espacio el mercado del alquiler provoca que se consolide como el caso más paradigmático del contexto residencial actual. Como se puede observar, el distrito Centro, no sólo era el espacio en dónde el porcentaje de vivienda habitual en alquiler era el más elevado $(39,55 \%)$ y su precio medio el más alto $(13,4 € / \mathrm{m} 2)$, sino que también es dónde mayor ha sido el incremento relativo del mismo desde 2013 a 2016 (32,2\%).

- El segundo conglomerado, hace referencia a aquellos distritos centrales, pertenecientes a la Almendra Central, así como al distrito de Moncloa-Aravaca, en donde el alquiler tiene también una presencia alta entre los hogares $(23,3 \%)$ y cuyos precios siguen a los del distrito Centro tanto en el orden de magnitud $(11,9$ $€ / \mathrm{m} 2)$ como en el crecimiento relativo experimentado entre 2013 y 2016 (25,9\%).

- El tercer conglomerado, designa a aquellos distritos fuera de la Almendra Central en donde el porcentaje de hogares viviendo en alquiler ya no es tan alto como en los conglomerados anteriores $(17,86 \%)$ y el precio medio del alquiler desciende a los $9,66 € / \mathrm{m} 2$. En cuanto al crecimiento de los precios hay que destacar que es el conglomerado en donde se registra la menor subida $(7,84 \%)$.

- El cuarto conglomerado, se encuentra compuesto por el resto de distritos fuera de la Almendra Central en dónde menor es la proporción de alquiler (15,55\%) y más asequible es el acceso a esta forma contractual $(8,85 € / \mathrm{m} 2)$ lo que, en el contexto actual de aumento de la demanda, explicaría el mayor crecimiento de precios que experimenta con respecto al conglomero anterior $(16,64 \%)$. 


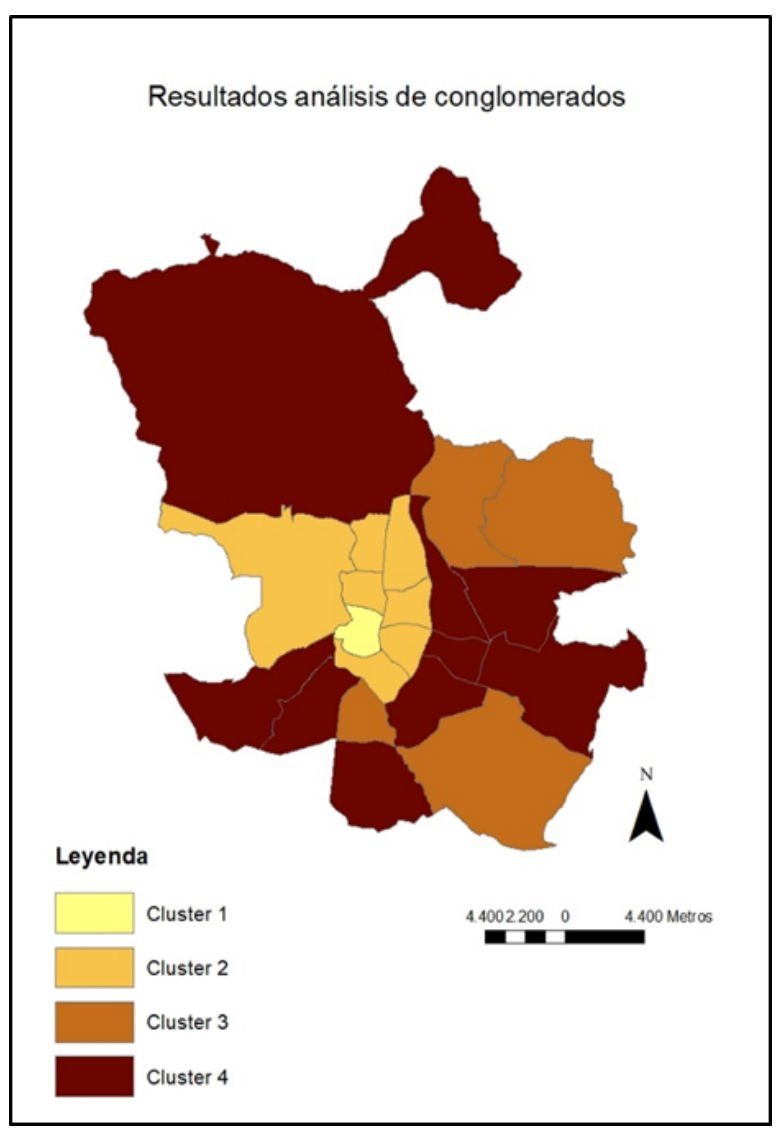

Mapa 1. Resultados del análisis de conglomerados

Gráfico 11 y 12. Dispersión entre el precio del alquiler y el incremento del alquiler según distritos y cluster de pertenencia y dispersión entre el precio del alquiler y el incremento del alquiler según distritos y cluster de pertenencia.
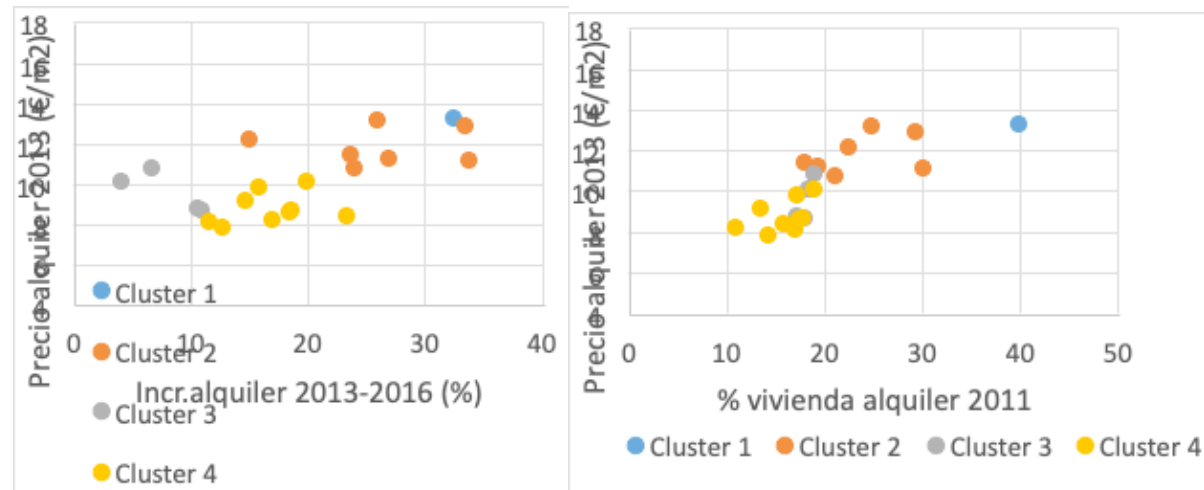

Fuente: Elaboración propia 
Tabla 3. Valores que adopta cada distrito para las variables representadas en los gráficos de dispersión.

\begin{tabular}{|c|c|c|c|c|}
\hline Clusters & Distritos & $\begin{array}{c}\text { Incr.alquiler } \\
\text { 2013-2016 (\%) }\end{array}$ & $\begin{array}{l}\text { Precio alquiler } \\
2013(€ / \mathrm{m} 2)\end{array}$ & $\begin{array}{c}\% \text { vivienda } \\
\text { alquiler } 2011\end{array}$ \\
\hline Cluster 1 & Centro & 32,22 & 13,38 & 39,55 \\
\hline \multirow{7}{*}{ Cluster 2} & Arganzuela & 23,74 & 10,89 & 20,81 \\
\hline & Chamartín & 14,81 & 12,27 & 22,16 \\
\hline & Chamberí & 33,21 & 13 & 29,05 \\
\hline & Moncloa & 26,76 & 11,36 & 19,1 \\
\hline & Retiro & 23,39 & 11,52 & 17,79 \\
\hline & Salamanca & 25,71 & 13,29 & 24,46 \\
\hline & Tetuán & 33,59 & 11,22 & 29,79 \\
\hline \multirow{4}{*}{ Cluster 3} & Barajas & 3,86 & 10,18 & 18,03 \\
\hline & Hortaleza & 6,49 & 10,9 & 18,74 \\
\hline & Usera & 10,3 & 8,84 & 17 \\
\hline & Villa De Vallecas & 10,71 & 8,75 & 17,67 \\
\hline \multirow{9}{*}{ Cluster 4} & Carabanchel & 18,41 & 8,81 & 17,59 \\
\hline & Ciudad Lineal & 19,66 & 10,22 & 18,63 \\
\hline & Fuencarral & 15,58 & 9,88 & 16,82 \\
\hline & Latina & 23,12 & 8,45 & 15,46 \\
\hline & Moratalaz & 16,66 & 8,33 & 10,57 \\
\hline & Puente De Vallecas & 18,24 & 8,64 & 17,15 \\
\hline & San Blas & 14,4 & 9,28 & 13,23 \\
\hline & Vicálvaro & 11,28 & 8,18 & 16,62 \\
\hline & Villaverde & 12,47 & 7,93 & 13,96 \\
\hline
\end{tabular}

Por tanto, cabe establecer la conclusión de que a mayor centralidad mayor es el cambio sufrido en el mercado residencial del alquiler de forma que, el acceso al mismo, tiende a complicarse más no sólo por el mayor precio que presenta sino también por su mayor crecimiento en términos relativos. Lejos de ser independiente, esta dinámica espacial conlleva serias dificultades en el acceso a la vivienda para los hogares, sobre todo para aquellos más dependientes de este régimen de tenencia, como son los conformados por los más jóvenes, ya que como se muestra en el análisis de conglomerados son las zonas más centrales de la ciudad las que congregan más vivienda en alquiler lo que promueve situaciones de precariedad residencial que necesariamente afectan a los procesos de distribución de los grupos sociales en el espacio.

¿De qué modo se relacionan las dinámicas espaciales del mercado del alquiler con la distribución espacial de los grupos sociales? Dada la enorme segmentación espacial del mercado de vivienda y sus dinámicas, el análisis de su relación con la distribución residencial de la población en el espacio se vuelve imprescindible a la hora de estudiar las crecientes problemáticas residenciales a las que se enfrenta la población en su acceso a la vivienda, especialmente aquella conformada por los grupos sociales más vulnerables. 
A través del análisis de las pautas de localización residencial de la población, se puede observar cómo, en términos generales y en concordancia con las transformaciones espaciales que se producen en el mercado del alquiler (cluster residencial), se asiste a un proceso de descentralización poblacional, que afecta al distrito Centro (cluster 1), en donde la presión sobre la oferta de alquiler, el nivel y el crecimiento de precios es mayor. De esta forma, se constata la estrecha relación que guardan los procesos actuales de pérdida de residentes en las zonas centrales de la ciudad, en beneficio de una población flotante, con la transformación del mercado de alquiler (Ardura, 2017). Por tanto, la vivienda vuelve a actuar como eje vertebrador fundamental en las nuevas pautas de gentrificación que sufre sobre todo el Centro de Madrid y que no se limitan ya sólo a un proceso de aburguesamiento de sus residentes sino también a un proceso de turistificación que expulsa a los vecinos (Janoschka, 2018).

Gráfico 13. Variación del peso poblacional de cada cluster residencial con respecto al conjunto de la ciudad de Madrid. 2013-2016

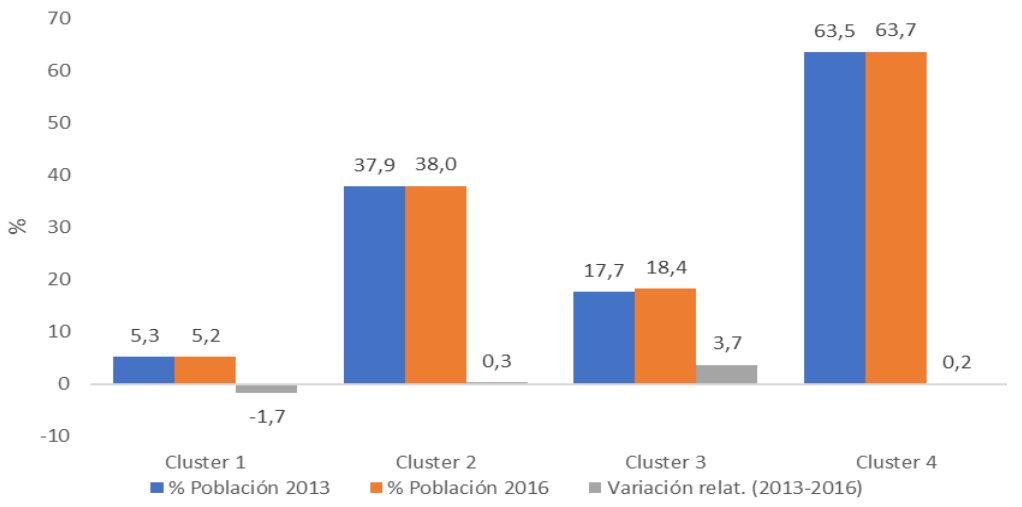

Fuente: Padrón de habitantes

Pero la tendencia descentralizadora que vive Madrid no afecta de forma igualitaria a todos los grupos sociales lo cual resulta lógico si se tiene en cuenta el sistema liberal que articula la provisión de vivienda y las tendencias del mercado de alquiler en los últimos años. Por un lado, y pese a que en el presente existan iniciativas que traten de revertir la situación, desde las instituciones públicas madrileñas se ha asistido a un proceso de residualización de la vivienda social en alquiler, que se refleja no sólo por la falta de producción de vivienda en el sector sino también por la privatización de la escasa vivienda social existente (García Calderón y Abellán, 2016), lo que previsiblemente traduce en un agravamiento de la desprotección residencial que ya sufre la población más vulnerable. Por otro, la creciente inversión privada especulativa que trata de beneficiarse tanto de la demanda residencial de alquiler, para incrementar los precios, como del auge del turismo y las viviendas vacacionales para maximizar los beneficios de las rentas, mediante la reconversión de uso de vivienda habitual en vacacional, no deja de poner en riesgo a la población más vulnerable y más dependiente del alquiler.

Tal cómo se observa en las siguientes tablas, la relación entre el cluster residencial y los cambios poblacionales demuestra como los grupos sociales más dependientes del alquiler, por ser los más vulnerables en términos económicos, son los que en términos relativos experimentan un descenso poblacional mayor cuanto más céntrica es la localización: 
En función de la ocupación, las categorías menos cualificadas no sólo son las que en menor proporción se localizan en las zonas céntricas sino que además son las que de forma más evidente descienden su presencia en términos relativos. De este modo, el distrito Centro, correspondiente con el primer cluster, registra el mayor descenso relativo $(-5,3 \%)$ de categorías de menor cualificación, seguidas de las ocupaciones medidas $(-4,5 \%)$ y las altas $(-1,8 \%)$, lo que a su vez revela como la fase actual del proceso de gentrificación afecta también a parte de población que representó su surgimiento. La misma dinámica se produce en el resto de distritos pertenecientes a la Almendra Central y el distrito de Moncloa-Aravaca, correspondientes con el segundo cluster, con una disminución relativa de las ocupaciones de menor cualificación del $2,4 \%$, seguidas de las categorías medias $(-1,7 \%)$ y altas $(-0,6 \%)$. Por el contrario, el resto de clusters residenciales muestran una tendencia poblacional creciente, sobre todo el tercer cluster, ya que en el cuarto sólo experimentan un leve crecimiento las ocupaciones medias y bajas.

Tabla 4. Relación entre el cluster residencial y la evolución de la población en base a la ocupación en la ciudad de Madrid.

\begin{tabular}{|l|c|c|c|c|c|c|c|c|c|}
\hline Clusters & $\begin{array}{c}\text { Ocup. } \\
\text { alta (\%) } \\
\mathbf{2 0 1 3}\end{array}$ & $\begin{array}{c}\text { Ocup. } \\
\text { alta (\%) } \\
\mathbf{2 0 1 6}\end{array}$ & Var.rel. & $\begin{array}{c}\text { Ocup. } \\
\text { media } \\
\mathbf{( \% )}\end{array}$ & $\begin{array}{c}\text { Ocup. } \\
\text { media } \\
\mathbf{( \% )}\end{array}$ & Var.rel. & $\begin{array}{c}\text { Ocup. } \\
\text { baja } \\
\mathbf{( \% )} \\
\mathbf{2 0 1 3}\end{array}$ & $\begin{array}{c}\text { Ocup. } \\
\text { baja } \\
\mathbf{2 0 1 6}\end{array}$ & Var.rel. \\
$\mathbf{2 0 1 6}$ & & \\
\hline Cluster 1 & 4,84 & 4,75 & $\mathbf{- 1 , 8}$ & 4,4 & 4,2 & $\mathbf{- 4 , 5}$ & 3,8 & 3,6 & $\mathbf{- 5 , 3}$ \\
\hline Cluster 2 & 41,8 & 41,5 & $\mathbf{- 0 , 6}$ & 27,5 & 27,1 & $\mathbf{- 1 , 7}$ & 17,2 & 16,8 & $\mathbf{- 2 , 4}$ \\
\hline Cluster 3 & 13,0 & 13,5 & $\mathbf{3 , 6}$ & 15,4 & 15,7 & $\mathbf{2 , 2}$ & 16,4 & 16,7 & $\mathbf{1 , 9}$ \\
\hline Cluster 4 & 40,4 & 40,2 & $\mathbf{- 0 , 3}$ & 52,7 & 53,0 & $\mathbf{0 , 6}$ & 62,5 & 62,8 & $\mathbf{0 , 5}$ \\
\hline
\end{tabular}

Fuente: Elaboración propia a partir de los datos de la Seguridad Social

En función de la nacionalidad y en base al mayor nivel de desagregación que presenta esta categoría con respecto al disponible para el cálculo del esfuerzo de acceso, se aprecia que, en el primer cluster, el mayor descenso relativo de población se produce entre la población extranjera $(-4,2 \%)$, concretamente entre la población procedente de países menos enriquecidos $(-6,7 \%)$, ya que de hecho los provenientes de países más enriquecidos no sólo no disminuyen su peso sino que lo incrementan en un 5,5\%, contradiciendo así las tenencias de la población en general. El resto de los distritos localizados en una posición central y, englobados en el segundo cluster, experimentarían un ligero incremento relativo de la población española $(0,3 \%)$ mientras que la población extranjera, en general, seguiría registrando unas tasas negativas $(-1,5 \%)$ que responden, en este caso, a las pautas llevadas a cabo por la población extranjera procedente de países enriquecidos $(-0,9 \%)$ pero sobre todo a las experimentadas por la población proveniente de países menos enriquecidos (-1,6\%). En el caso de las dinámicas espaciales de la población acontecidas en distritos más alejados del centro, el tercer cluster, refleja sobre todo un fuerte crecimiento de la población española $(3,0 \%)$, así como de la extranjera $(2,8 \%)$ como consecuencia del notable incremento de la población procedente de los países menos enriquecidos $(3,4 \%)$ puesto que los provenientes de los países más enriquecidos muestran también, en este caso, un descenso poblacional $(-1,9 \%)$. Por último, el cuarto cluster, reflejaría un descenso relativo de la población española $(-0,9 \%)$ siendo sólo la extranjera $(0,6 \%)$, concretamente la de los países menos enriquecidos la que aumenta su peso con un incremento relativo del $0,6 \%$, ya que con respecto a la población procedente de países enriquecidos sus tasas siguen siendo negativas $(-0,4 \%)$, a excepción de su crecimiento en el distrito centro. 
Tabla 5. Relación entre el cluster residencial y la evolución de la población en base a la nacionalidad

\begin{tabular}{|c|c|c|c|c|c|c|c|c|c|c|c|c|}
\hline Clusters & $\begin{array}{l}\sum_{i}^{m} \\
\dot{\delta} \\
\text { ஸ் }\end{array}$ & $\begin{array}{l}\stackrel{0}{\delta} \\
\text { N } \\
\text { 요 } \\
\text { ய }\end{array}$ & $\begin{array}{l}\frac{\dot{\Phi}}{2} \\
\frac{10}{5}\end{array}$ & $\begin{array}{l}\text { m } \\
\text { N } \\
\text { 爻 }\end{array}$ & 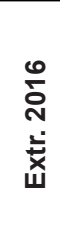 & $\begin{array}{l}\frac{\dot{\Phi}}{\square} \\
\frac{\pi}{\pi}\end{array}$ & 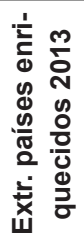 & 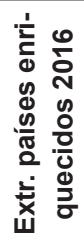 & $\begin{array}{l}\dot{\Phi} \\
\frac{0}{5} \\
\text { ग }\end{array}$ & 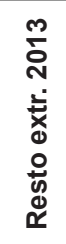 & 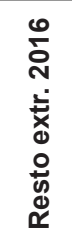 & $\begin{array}{l}\text { बं } \\
\frac{0}{\overline{0}}\end{array}$ \\
\hline Cluster1 & 3,8 & 3,7 & $-1,4$ & 6,6 & 6,4 & $-4,2$ & 13,5 & 14,2 & 5,5 & 5,9 & 5,5 & $-6,6$ \\
\hline Cluster 2 & 31,1 & 31,2 & 0,3 & 27,8 & 27,4 & $-1,5$ & 42,0 & 41,7 & $-0,9$ & 26,2 & 25,8 & $-1,6$ \\
\hline Cluster 3 & 14,3 & 14,7 & 3,0 & 13,4 & 13,8 & 2,8 & 13,2 & 12,9 & $-1,9$ & 13,5 & 13,9 & 3,4 \\
\hline Cluster 4 & 51,0 & 50,5 & $-0,9$ & 52,1 & 52,4 & 0,6 & 31,3 & 31,2 & $-0,4$ & 54,4 & 54,8 & 0,6 \\
\hline
\end{tabular}

Fuente: Elaboración propia a partir de los datos del Padrón de habitantes

Las pautas de distribución de la población en función de la edad resultan más controvertidas en comparación con las tendencias espaciales que demuestran los grupos sociales en función de la ocupación y la nacionalidad, lo cual es, por otro lado, lógico si se tiene en cuenta la influencia que juega, en la edad, no sólo la variable económica sino también el ciclo del hogar y las estrategias residenciales asociadas al mismo (Leal y Domínguez 2008). De esta forma, la mayor ausencia de compromisos familiares entre la población joven la convierte en más proclive a la convivencia en tipologías de hogar multipersonales (Echaves, 2016) lo que serviría para contrarrestar, aunque sólo sea en parte y de manera transitoria, el encarecimiento de la vivienda en alquiler. Este hecho, junto a una posible segmentación socioeconómica entre los jóvenes más adultos, podría explicar el incremento que experimenta la proporción de población entre 25 y 34 años en el primer cluster, correspondiente con el distrito Centro. Sin embargo, no ocurre lo mismo con la población más joven, menor de 25 años, ya que es la que experimenta un mayor descenso relativo de su presencia en el primer cluster $(-4,5 \%)$ ratificándose así el hecho de que los grupos sociales más dependientes del alquiler son los que experimentan una mayor disminución de su población en las zonas centrales en dónde éste tiene mayor peso.

Tabla 6. Relación entre el cluster residencial y la evolución de la población en base a la edad

\begin{tabular}{|c|c|c|c|c|c|c|c|c|c|c|c|c|c|c|c|}
\hline Clusters & $\begin{array}{l}\stackrel{m}{\delta} \\
\stackrel{N}{0} \\
\stackrel{N}{1}\end{array}$ & $\begin{array}{l}0 \\
\text { ○ } \\
\stackrel{N}{N} \\
\text { in }\end{array}$ & $\frac{\dot{\Phi}}{\frac{\dot{0}}{5}}$ & 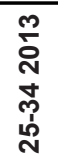 & $\begin{array}{l}\stackrel{0}{0} \\
\text { N } \\
\text { ஸे } \\
\text { ஸे }\end{array}$ & 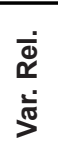 & 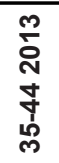 & $\begin{array}{l}\stackrel{0}{0} \\
\text { O } \\
\text { 寸 } \\
\text { ம் }\end{array}$ & 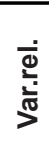 & 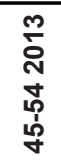 & 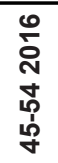 & $\begin{array}{l}\frac{\dot{0}}{\mathbf{D}} \\
\frac{10}{5}\end{array}$ & $\begin{array}{l}\stackrel{m}{0} \\
\stackrel{N}{0} \\
0 \\
+\end{array}$ & 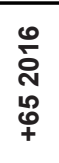 & $\begin{array}{l}\text { ఏ் } \\
\frac{1}{5}\end{array}$ \\
\hline Cluster 1 & 3,9 & 3,8 & $-4,5$ & 6,2 & 6,3 & 1,6 & 5,3 & 5,3 & 0,7 & 4,4 & 4,3 & $-1,6$ & 3,7 & 3,6 & $-2,6$ \\
\hline Cluster 2 & 29,2 & 29,4 & 0,9 & 32,7 & 33,3 & 2,0 & 28,2 & 28,8 & 2,2 & 29,5 & 28,4 & $-3,7$ & 33,3 & 33,0 & $-1-1$ \\
\hline Cluster 3 & 14,4 & 14,3 & $-0,8$ & 13,9 & 13,8 & $-0,8$ & 15,7 & 16,5 & 4,8 & 14,0 & 14,7 & 4,9 & 12,1 & 12,5 & 3,1 \\
\hline Cluster 4 & 52,5 & 52,5 & 0,0 & 47,2 & 46,6 & $-1,3$ & 50,8 & 49,4 & $-2,8$ & 52,1 & 52,5 & 0,9 & 50,8 & 50,9 & 0,1 \\
\hline
\end{tabular}

Fuente: Elaboración propia a partir de los datos del Padrón de habitantes

Por tanto, el aumento de los precios de la vivienda en el mercado del alquiler, no sólo ha golpeado con mayor dureza a los grupos más vulnerables a través de su esfuerzo de acceso a la vivienda sino también a través de sus posibilidades residenciales en el espacio urbano en el que se demuestra la creciente desigualdad desde abajo a partir del proceso de descentralización que vive la ciudad de Madrid. 


\section{Conclusiones}

En general, se asiste a un proceso de creciente dificultad en el acceso a la vivienda que afecta de forma desigual a los distintos grupos sociales ya que son los más vulnerables, en términos económicos, los que tienden a sufrir en mayor medida los cambios acontecidos en los últimos años en el mercado de la vivienda a través del régimen de tenencia. Por un lado, su acceso a la propiedad sigue siendo casi inviable, dada su mayor precariedad laboral y las dificultades de ahorro y financieras que atraviesan y, por otro, la alternativa tradicional que en sus casos ha jugado el alquiler se complica cada vez más, dada la escasez de oferta y el encarecimiento que presenta la misma.

El mayor impacto del crecimiento del esfuerzo del alquiler entre los grupos sociales más vulnerables tiene además una importante componente espacial derivada del comportamiento desigual del mercado de la vivienda en el espacio. En este sentido, si bien se produce una tendencia generalizada a la descentralización, que es inseparable de la transformación sufrida en el sector de la vivienda en alquiler, son sobre todo los grupos más vulnerables los que sufren esta situación dada su mayor dependencia del mercado del alquiler y el mayor encarecimiento que presenta el mismo en las zonas más céntricas, dónde mayor concentración de oferta ha habido tradicionalmente. No obstante, cabe resaltar cómo, la enorme presión residencial a la que es sometido en centro de la Ciudad, mediante la subida de precios y los efectos de la turistificación, se extiende también al resto de grupos sociales, muchos de ellos "gentrificadores" en una etapa anterior. 


\section{Referencias bibliográficas}

Allen et al. (2004). Housing and welfare in Southern Europe. London: Blackwell. https:// doi.org/10.1002/9780470757536.

Allen, J. (2006). Welfare Regimes, Welfare Systems and Housing in Southern Europe, International Journal of Housing Policy $n^{\circ} 6$ (3), pp. 251-277. https://doi. org/10.1080/14616710600973102.

Arbaci, S. (2008). Hacia la construcción de un discurso sobre la inmigración en las ciudades del sur de Europa. La política urbanística y de vivienda como mecanismos estructurales de marginación étnica residencial. ACE: Architecture, City and Environment $\mathrm{n}^{\circ}$ 8, pp. 11-38.

Ardura, A. (2017) La incidencia de la proliferación del alojamiento turístico en viviendas en el centro de Madrid. $3^{\circ}$ encuentro de la red europea "Live the City!" Recuperado de: http://www.vivre-la-ville.fr/wp-content/uploads/2017/03/VivreLaVille-Madrid-2017 PonenciaTurismo-ES.pdf

Bankinter. (2018). La deuda de las familias españolas (datos). Recuperado de https:// blog.bankinter.com/economia/-/noticia/2018/8/13/deuda-familias-espanolas

Barlow, J. y Duncan, S. (1994). Success and Failure in Housing Provision. Oxford: Pergamon Press.

Cabrerizo, C; Sequera, J. y Bachiller, P.G. (2016). Entre la turistificación y los espacios de resistencia en el centro de Madrid: Algunas claves para (re)pensar la ciudad turística. Ecología política del turismo, $\mathrm{n}^{\circ} 52$, pp. 78-82.

Castles, F. G. y Ferrera, M. (1996). Home ownership and the welfare state: is southern Europe different?, South European Society and Politics, n¹ (2), pp.163-185.https:// doi.org/10.1080/13608749608539470.

Cea D’Ancona, Ma . (2002). Análisis Multivariable. Teoría y práctica en la investigación social. Madrid: Síntesis.

Díez, M. (2017). ¿Cómo afecta el turismo al precio del alquiler a residentes? Caso aplicado a la cuidad de Barcelona. Trabajo fin de grado, Universitat de Barcelona. Recuperado de: http://aracoop.coop/wp-content/uploads/TFG_Como_afecta_el_turismo_al_precio_del_alquiler_a_residentes.pdf.

Echaves, A. (2016). Juventud, emancipación residencial y sistema de provisión de vivienda: las divergencias autonómicas del modelo español. Tesis doctoral. Universidad Complutense de Madrid. Recuperado de: https://eprints.ucm.es/35557/1/T36818.pdf

Echaves, A. (2017). Emancipación residencial y sistema de provisión de vivienda: la heterogeneidad autonómica del modelo español. Revista Española de Investigaciones Sociológicas, n¹59, pp: 51-72. http://dx.doi.org/10.5477/cis/reis.159.51

Esping-Andersen, G. (1990). The Three Worlds of Welfare Capitalism. Cambridge: Polity Press \& Princeton: Princeton University Press.

Fernández Cordón, J. A. y Leal, J. (2014). Residential Behaviour in Spain. En: C. Bonvalet, V. Laflamme, y D. Arbonville, (eds.), Family and housing: Recent trends in France and Southern Europe. Oxford: The Bardwell Press.

FUNCAS, (2015). La deuda de las familias españolas. Recuperado de https://www.funcas.es/canalfinanciero/programas.aspx?file $=58$ 
García Calderón, I. y Abellán, J. (2016). El problema de la vivienda en el Madrid neoliberal. Políticas públicas y luchas por la vivienda en el contexto de la crisis urbana. Working paper series Contestes_cities, $n^{\circ} 5$. Recuperado de: http://contested-cities.net/ working-papers/wp-content/uploads/sites/8/2017/05/WPCC_160002_Madrid_final.pdf

Gil, J. y Sequera, J. (2018). Expansión de la ciudad turística y nuevas resistencias. El caso de Airbnb en Madrid. EMPIRIA. Revista de Metodología de Ciencias Sociales, $\mathrm{n}^{\circ}$ 41, pp: 15-32. https://doi.org/10.5944/empiria.41.2018.22602

Janoschka, M. (2018). Gentrificación en España Reloaded. Papers: Regió Metropolitana de Barcelona: Territori, estratègies, planejament:Gentrificació i dret a la ciutat, $n^{\circ} 60$, pp.25-33.

Kemeny, J. (1992).Housing and Social Theory. London: Routledge.

Kemeny, J. (1995). From Public Housing to the Social Market. London: Routledge. https:// doi.org/10.4324/9780203308554.

Leal, J. (2002). Segregación social y mercados de vivienda en las grandes ciudades. Revista Española de Sociología, n² 2, pp. 59-75

Leal, J. (2005). La política de vivienda en España. Documentación Social, n¹38, pp. 6380. ISBN: 84-8440-349-1.

Leal, J. y Domínguez, M. (2008). Transformaciones económicas y segregación social en Madrid. Ciudad y territorio, Estudios Territoriales, n 158, pp. 703-725.

Leal, J. y Martínez del Olmo, A. (2016). Tendencias recientes de la política de vivienda en España. Cuadernos de Relaciones Laborales, $n^{\circ} 35$ (1), pp. 15-41. http://dx.doi. org/10.5209/CRLA.54982

Lorente, R. y Guamán, A. (2018). Expansión de la temporalidad y erosión de la relación de empleo estándar en España: ¿La irrupción de un nuevo paradigma de relación de empleo?. Cuadernos de Relaciones Laborales, $n^{\circ} 36(1)$, pp. 35-63. http://dx.doi. org/10.5209/CRLA.59556

Méndez, R. y Plaza, J. (2016). Crisis inmobiliaria y desahucios hipotecarios en España: una perspectiva geográfica. Boletín de la Asociación de Geógrafos Españoles $n^{\circ} 71$, pp-99-127.http://dx.doi.org/10.21138/bage.2276

Módenes, J. A. y López-Colás, J. (2014). Cambio demográfico reciente y vivienda en España: ¿hacia un nuevo sistema residencial?.Revista Española de Investigaciones Sociológicas, $\mathrm{n}^{0} 148$, pp. 103-134. http://dx.doi.org/10.5477/cis/reis.148.103

Pareja-Eastway, M. y Sánchez- Martínez, M.T. (2011). El alquiler: una asignatura pendiente de la Política de Vivienda en España. Revista Ciudad y Territorio, n 167, pp. 53-70.

Pareja-Eastway, M. y Sánchez- Martínez, M.T. (2016). Alquiler privado como vivienda social en España. Revista Ciudad y Territorio, n 189, pp. 383-397.

Rodríguez, J. (2017) El despegue de los alquileres en España. Club de debates urbanos. Recuperado de: http://clubdebatesurbanos.org/wp-content/uploads/2017/03/JRL-ELDESPEGUE-DE-LOS-ALQUILERES.pdf

Rodríguez, J. (2018). El vacío estadístico del mercado del alquiler de viviendas. El siglo de Europa, $\mathrm{n}^{\circ}$ 1241. Recuperado de: http://www.elsiglodeuropa.es/siglo/historico/2018/1241/Index\%200pinion\%20Julio\%20Rodriguez\%20Lopez.html 
Rodríguez, R. y Espinoza, M. (2018). De la especulación al derecho a la vivienda. Más allá de las condiciones del modelo inmobiliario español. Madrid: Traficantes de Sueños

Taltavull, P. (2017). El sector de la vivienda: coyuntura y expectativas. Cuadernos de Información económica, n²60, pp. 47-60. 